The review found that there have been few strategic interventions that specifically address stigma and discrimination among MSM population despite their high HIV positive serostatus. Men having sex with Men are illegal in 31 Sub-Saharan African countries, potentially attracting the death penalty in four. There has been a disproportionately small amount of governmental funding allocated for targeted interventions among these populations in the region. The MSM populations usually have no access to relevant HIV/AIDS information and services, and many countries have not begun to recognise or address the needs of these men in the context of national HIV/AIDS prevention and control programmes.

We propose that the national governments may consider prioritising context-specific and culturally appropriate strategies and allocate budgets in their National AIDS Policies to address stigma \& discrimination faced by the MSM population and protect their rights in Sub-Saharan Africa.

\section{P6.037 MISSED OPPORTUNITIES FOR HIV TESTING IN CLINICAL SETTINGS: A SYSTEMATIC REVIEW OF COMPLIANCE WITH NATIONAL 2008 GUIDELINES IN THE UK}

doi:10.1136/sextrans-2013-051184.1191

R Elmahdi, S Gerver, H Ward. Imperial College London, London, UK

Background In 2011 there were 6,280 new HIV diagnoses in the UK, of which $47 \%$ were diagnosed late (CD4 cell count 2/1,000 adult population. We evaluated compliance with BHIVA-guidelines on HIV testing outside of STI and antenatal settings.

Methods We carried out a systematic review searching MEDLINE, EMBASE and conference abstracts using variations of "HIV", "testing" and "UK" to identify relevant studies, and used meta-analysis to calculate an overall HIV testing prevalence.

Results Thirty-three UK studies measuring HIV testing in BHIVAguideline recommended settings were identified. Overall, $37.9 \%$ of eligible patients had HIV tests. Thirteen studies reported levels of HIV test offer and uptake: in 10 studies $<50 \%$ of eligible patients were offered a test; of those offered, uptake ranged from $47.9 \%$ $100 \%$, with 11 reporting $>65 \%$ uptake. Twenty-one studies reported seropositivity (range: $0.0 \%-11.8 \%$ ).

Conclusion There appears to be poor compliance with the 2008 BHIVA-guidelines for testing outside of STI and antenatal clinics. Over $60 \%$ of eligible patients remained untested. Test offer rates were lower than uptake, suggesting clinician-barriers may be stronger than patient-barriers to increasing testing. Greater clinician training in routine HIV testing and improved HIV testing surveillance in clinical settings may be required to further encourage increased HIV testing in the UK.

\section{P6.038 TECHNICAL SUPPORT FOR CLINICAL SERVICES OF A LARGE SCALE HIV PREVENTION PROGRAMIME FOR KEY POPULATIONS IN INDIA}

doi:10.1136/sextrans-2013-051184.1192

'A Das, ${ }^{1} \mathrm{M}$ Parthasarathy, ${ }^{1} \mathrm{P}$ Narayanan, ${ }^{2} \mathrm{~T}$ Wi, ${ }^{3} \mathrm{~S}$ Kumta, ${ }^{3} \mathrm{G}$ Dallabetta. ${ }^{1} \mathrm{FHI} 360$, New Delhi, India; ' $W H O$, Geneva, Switzerland; ' ${ }^{3}$ Bill \& Melinda Gates Foundation, New Delhi, India

Background Avahan was a focused HIV prevention programme implemented across six states in India by seven lead agencies through 129 local NGOs, providing services to 321,000 individuals from key populations. Clinical services for STIs were an important component of Avahan's intervention package.

Methods Technical support was provided by a centralised agency to lead agencies' STI staff who directly supervised NGO clinical services. The approach during the first phase (2005-2009) of 'build and operate' included developing standardised guidelines, training, quality assurance and quality improvement, and using monitoring data to improve the programme. During the final phase (2009-2013) of transitioning to government support, the strategy was to ensure that services were restructured to align with national guidelines, generate and provide evidence towards advocacy for improvement of the national programme.

Results In 2005-2009, 431,434 individuals made 2.7 million clinic visits. The annual average number of clinic visits by individuals increased from 1.6 to 3.5 , and the proportion of visits for STI syndromes decreased from $52.5 \%$ to $11.8 \%$. Verbal screening for tuberculosis (TB) identified 6,879 TB suspects of whom 1,565 were diagnosed with active TB. The quality monitoring of Avahan clinics showed an increased score from 2.21 to 3.82 (on a scale of $0-5$ ). The introduction of a point of care test for syphilis doubled the proportion of clinic attendees screened from 2007 to 2009. In the transition phase, revised operational guidelines were developed to align with national guidelines and a nurses' training was conducted to address 'task shifting'. The national programme adapted the Avahan guidelines for STI management among key populations.

Conclusion A centralised technical support agency has a pivotal role in ensuring standardised and high quality services. Large scale and national programmes would benefit from collaborating with independent technical units to outsource some of the work of implementation.

\section{P6.039 WHY DID PLAUSIBLE RESEARCH EVIDENCE FAIL TO INFORM POLICY? A LESSON FROM MALE CIRCUMCISION EVIDENCE ON EFFICACY FOR THE PREVENTION OF HIV IN MALAWI}

doi:10.1136/sextrans-2013-051184.1193

\section{A David. UNC Project, Kamuzu Central Hospital, Lilongwe, Malawi}

On the basis of three randomised controlled trials showing that male circumcision (MC) is effective in reducing HIV transmission, WHO/UNAIDS recommend that high HIV prevalence countries include MC in their HIV prevention programmes. Malawi delayed to adopt such a policy.

This study examines evidence-to-policy processes in Malawi, using $\mathrm{MC}$ as a case study. Separate but similar semi-structured interviews were conducted with national health policy decisionmakers, researchers, politicians and traditional leaders regarding the decision-making processes concerning the adoption of $\mathrm{MC}$ and, as a comparison, to the adoption of acyclovir for management of STIs and nevirapine for PMTCT.

We observed that although policy-makers are aware of the evidence in Sub-Saharan Africa that MC reduces the risk of HIV acquisition among circumcised men, the adoption of a MC policy is resisted. Policy-makers and international actors are embroiled in policy controversies that have historical resonance in Malawi; MC is perceived as something that comes from outside--a Western 'imposition' is being forced onto Malawians. Malawi was settled by Muslims and by non-circumcised Christians; ethnic and religious rivalries have characterised politics since Independence. Thus, politicians have framed $\mathrm{MC}$ in-terms of tribal and religious identities. In contrast, acyclovir and nevirapine were perceived as culturally neutral, and were accepted without debate.

The call for evidence-based policy is likely to be received as unproblematic when, as with acyclovir and nevirapine, the issue does not touch controversies especially those related to religion and ethnic politics. But, when a core issue that identifies ethnicities is at the centre of controversy and it threatens what powerful local actors consider being in their best interest - there is invariably opposition. Thus reframing a new policy to minimise controversy - and in the case of MC, from "MC" to "voluntary medical MC" might result in actors' reflection and thus provide a path towards resolution. 